\title{
PESQUISA MUNICIPAL UNIFICADA instrumento para o estudo da gestão municipal
}

\author{
Aurílio Sérgio Costa Caiado \\ Resumo: A Pesquisa Municipal Unificada - PMU, realizada pela Fundação Seade desde 1992, disponibiliza \\ um grande conjunto de informações sobre gestão municipal, possibilitando análises de todos os municípios \\ paulistas. O artigo apresenta as principais características da PMU e desenvolve um tema com estatísticas cons- \\ truídas a partir daquela base de dados. \\ Palavras-chave: gestão municipal; incentivos municipais; localização industrial; guerra fiscal. \\ Abstract: The Unified Municipal Survey - PMU - carried out by Fundação Seade since 1992, provides a large \\ body of information regarding municipal governance, making possible an analysis of all of São Paulo State's \\ municipalities. The article presents the PMU's principal characteristics and develops a theme using statistics \\ built from that data base. \\ Key words: municipal governance; municipal incentives; industrial localization; tax war.
}

$\mathrm{D}$ esde a década de 90, tem-se ampliado a atenção e os estudos sobre os municípios, notadamente no que se refere à gestão municipal. Com a promulgação da Constituição Federal, em 1988, os municípios adquiriram status de entes federativos além de ampliadas suas competências e estabelecidos os processos de descentralização de ações e do poder decisório. A descentralização possibilitou, aos municípios, acesso a maior parcela de recursos públicos, mas, ao mesmo tempo, a atuação direta foi ampliada em áreas que antes eram de responsabilidade do governo estadual ou federal.

Com as novas responsabilidades e atribuições específicas assumidas pelos municípios, aumentaram tanto as exigências de profissionalização da gestão municipal quanto a necessidade de instituição de controles democráticos/ populares da ação pública.

A aprovação da Lei de Responsabilidade Fiscal (Lei Complementar $\mathrm{n}^{\circ} 101$, de 4 de maio de 2000), que fixa limites para gastos públicos, nas três esferas de governo, ampliou ainda mais a necessidade de profissionalização e transparência na gestão pública, em particular na municipal, e requereu esforço adicional de "enxugamento" da máquina pública.
No entanto, a nação assistiu, durante os anos 90, à implementação de propostas liberalizantes que redundaram na redução da presença do Estado, flexibilização e desregulamentação das regras de concorrência, abertura do mercado e privatização de ativos públicos, com impactos significativos na gestão municipal, sobretudo em municípios de grande ou médio portes.

Em síntese, uma miríade de fatores - aqui só foram listados os mais importantes - contribuiu para que houvesse grandes alterações no padrão de gestão municipal na última década do século XX. Esse "novo padrão", ainda em processo de constituição e consolidação, pode ser observado pela análise da estrutura e da forma de articulação da ação nos diversos setores executores de políticas públicas.

Para acompanhar esse processo e fornecer à sociedade paulista informações estruturadas sobre a gestão de cada um de seus municípios, a Fundação Seade, em 1992, unificou as diversas pesquisas setoriais de abrangência municipal, adaptando os diversos instrumentos de coleta a um mesmo padrão metodológico e consolidando-os em uma pesquisa única, denominada Pesquisa Municipal Unificada. 


\section{PESQUISA MUNICIPAL UNIFICADA}

A heterogeneidade dos 645 municípios paulistas repercute na configuração de suas organizações administrativas e na complexidade e abrangência das ações públicas municipais. ${ }^{1}$ Igualmente diferenciadas são a capacidade e a disponibilidade política das prefeituras e das comunidades perante novas atribuições. O grande desafio da equipe técnica da PMU foi estruturar uma pesquisa que desse conta da heterogeneidade e diversidade de ação dos municípios e, ao mesmo tempo, fosse flexível o suficiente para acompanhar as mudanças e transformações na gestão. Essas duas dimensões tornam estratégica a PMU, seja para contemplar a profunda diferenciação das realidades municipais, seja pela crescente importância da instância municipal na gestão das políticas públicas.

A pesquisa tem por campo de ação o município e é censitária, com informações coletadas em todos os municípios paulistas. Os informantes são as prefeituras municipais, incluindo os órgãos da administração direta e indireta, o que garante informações precisas e possibilita aquilatar o desempenho delas diante do novo papel que os municípios vêm assumindo na administração das políticas públicas, principalmente as de cunho social. A amplitude dos assuntos captados, a profundidade das questões levantadas, bem com a grande interface existente entre elas, permitem análises sobre as principais questões da gestão pública e podem orientar a formulação de políticas públicas.

A pesquisa está organizada em 13 grandes temas, cada qual com um questionário dirigido à área ou setor específico da prefeitura. Os questionários são: Assistência e Desenvolvimento Social; Comunicações e Informática; Cultura, Esporte e Turismo; Educação; Estrutura Administrativa; Estrutura Urbana; Finanças Públicas Municipais; Guarda Municipal; Habitação; Limpeza Pública; Saneamento Básico; Saúde; e Transportes Municipais. Está sendo estudada a inclusão de dois novos temas: Abastecimento e Segurança Alimentar; e Incentivo ao Desenvolvimento Econômico e Empreendedorismo.

É importante ressaltar que as questões referentes ao meio ambiente são coletadas em três questionários distintos: saneamento básico, limpeza pública e estrutura urbana, porque esse tema é tratado por mais de uma instância nas prefeituras e a estratégia da pesquisa é encaminhar um questionário específico para cada setor responsável por respondê-lo.

Outra questão importante a ser ressaltada é a estratégia adotada pela pesquisa de só perguntar o que não está disponível em outra fonte pública de informações. Isso tem permitido certa redução no número de questões, sem prejuízo da qualidade das análises.

O amplo espectro de questões, em torno de 200 perguntas, possibilitaram a organização de uma base de dados com mais de duas mil variáveis para cada município. Essas informações estão disponíveis na página do Seade na Internet, no <http://www.seade.gov.br/pmu/> e têm apoiado a elaboração de vários produtos nos últimos anos, com destaque para o Índice Paulista de Responsabilidade Social - IPRS, feito em parceria com a Assembléia Legislativa do Estado de São Paulo.

São bem amplas as possibilidades de estudos sobre gestão municipal, valendo-se das informações coletadas pela PMU. Neste artigo, optou-se por apresentar uma análise sobre a atuação dos municípios na atração de novos investimentos produtivos. Tema de grande atualidade, o esforço direto dos municípios por atração de novos investimentos tem-se ampliado nos últimos anos, quase numa reprodução, ao nível local, da "guerra fiscal" praticada por estados e a PMU é a única fonte de dados que possibilita análises desagregadas por porte e por localização regional dos municípios. ${ }^{2}$

\section{INSTRUMENTOS MUNICIPAIS DE INCENTIVO E RESTRIÇÃO À INSTAURAÇÃO DE EMPREENDIMENTOS ${ }^{3}$}

A concessão de benefícios fiscais para a atração de investimentos é uma prática relativamente antiga que se intensificou na década de 90, transformando-a em verdadeira guerra na disputa entre Estados e localidades, principalmente entre 1993 e 1994. Dessa forma, os governos subnacionais têm buscado influenciar a decisão locacional dos investimentos privados, com um verdadeiro "leilão de localização" em que Estados e municípios disputam acirradamente a instalação de uma nova empresa em seus territórios.

Estudos comprovam que as decisões de investimentos privados são tomadas independentemente dos incentivos fiscais. Alguns fatores determinam essas decisões: a qualidade da infra-estrutura viária e de telecomunicações, proximidade com o mercado consumidor, qualificação da mão-de-obra local, etc. (Prado; Cavalcanti, 1998). Com base nesses critérios, a empresa escolhe um local "ótimo" para a instalação da unidade industrial. Assim, para aceitar a condição de uma localização afastada, ela exige um volume de benefícios que cubra não apenas o "custo de 
afastamento" mas também ofereça um "prêmio" adicional pelos riscos de uma opção que passa a depender dos compromissos assumidos por um governo. Como os governos locais não conhecem a preferência alocativa das empresas, abre-se espaço para o leilão. Além disso, “é elemento central da estratégia privada da guerra fiscal construir a imagem do 'empate' entre locações alternativas, a fim de remeter para a competição entre incentivos o papel decisório final" (Prado; Cavalcanti, 1998: 44). Tal postura obriga Estados e municípios a maximizarem os incentivos oferecidos.

Isso significa que os incentivos fiscais até podem promover o deslocamento de um investimento dentro do país ou de um Estado, no entanto isso se dá com elevado custo fiscal. Se o investimento já estava programado para ser realizado em determinado Estado/município, o deslocamento é feito com o desperdício de recursos públicos, pois abre-se mão de receita tributária e de recursos orçamentários para assegurar a instalação de um investimento que já ocorreria (Varsano, 1997). Mesmo se o investimento for bem-sucedido, com efeitos positivos para a economia local, acarretará prejuízo a toda sociedade, pois a arrecadação e a receita orçamentária global passarão por redução. Além disso, o caso extremo pode ocorrer se a locação preferencial for a mesma em que a empresa decida se instalar após a disputa fiscal. Utilizando o argumento dos autores citados, em tal caso extremo, os incentivos fiscais representariam apenas um generoso prêmio para a empresa, transferência líquida de recursos públicos para empresas privadas (Caiado, 2002).

No caso do Estado de São Paulo, o governo praticamente esteve fora do "leilão locacional" pois, em muitos setores industriais, o denominado "ótimo locacional" definido pela empresa já é o Estado. Contudo, tem-se acirrado a disputa entre os municípios paulistas, com ampliação da oferta de incentivos.

A PMU apresenta, desde 1995, informações sobre os principais mecanismos de incentivo à instalação de empreendimentos utilizados pelos municípios paulistas, tornando-se importante referência para análise do tema. Além disso, a pesquisa contribui para o entendimento da forma como os municípios inserem-se no processo geral de guerra fiscal.

É crescente e significativa a parcela dos municípios do Estado que se valem de algum mecanismo de incentivo à instalação de empreendimentos (Tabela 1). Em 1995, 37\% dos municípios existentes utilizavam esses mecanismos e, em 1999, 51\%. Os incentivos são ofertados, sobretudo, por municípios de médio ou grande portes. Em 1999, mais de $70 \%$ dos municípios com mais de 50 mil habitantes possuíam instrumentos de incentivo à instalação de empreendimentos. $\mathrm{O}$ uso desses instrumentos concentra-se, principalmente, nos municípios com mais de 500 mil habitantes. Dos oito municípios nessa faixa de população, em 1999, somente São Bernardo do Campo não possuía nenhum instrumento com esse propósito. No entanto, é

TABELA 1

Municípios com Mecanismos de Incentivo à Implantação de

Empreendimento, segundo Porte Populacional Estado de São Paulo - 1995-1999

\begin{tabular}{|c|c|c|c|c|c|c|}
\hline \multirow{3}{*}{ População } & \multicolumn{2}{|c|}{ Número de Municípios } & \multicolumn{4}{|c|}{ Mecanismos de Incentivo à Implantação de Empreendimentos } \\
\hline & \multirow{2}{*}{1995} & \multirow{2}{*}{1999} & \multicolumn{2}{|c|}{1995} & \multicolumn{2}{|c|}{1999} \\
\hline & & & Possui & $\%$ & Possui & $\%$ \\
\hline Total & 625 & 645 & 231 & 37 & 329 & 51 \\
\hline Até 5 Mil Hab. & 167 & 180 & 36 & 22 & 66 & 37 \\
\hline Mais de 5 Mil a 10 Mil Hab. & 120 & 116 & 32 & 27 & 47 & 41 \\
\hline Mais de 10 Mil a 20 Mil Hab. & 119 & 117 & 43 & 36 & 62 & 53 \\
\hline Mais de 20 Mil a 50 Mil Hab. & 116 & 117 & 54 & 47 & 70 & 60 \\
\hline Mais de 50 Mil a 100 Mil Hab. & 50 & 53 & 33 & 66 & 39 & 74 \\
\hline Mais de 100 Mil a 250 Mil Hab. & 33 & 40 & 22 & 67 & 29 & 73 \\
\hline Mais de 250 Mil a 500 Mil Hab. & 14 & 14 & 8 & 57 & 10 & 71 \\
\hline Mais de 500 Mil Hab. & 6 & 8 & 3 & 50 & 6 & 75 \\
\hline
\end{tabular}

Fonte: Fundação Seade. Pesquisa Municipal Unificada - PMU. 
preciso observar que mesmo entre os municípios pequenos é alta a freqüência da aplicação de incentivos nos dois períodos pesquisados.

A utilização de incentivos a novos empreendimentos apresenta baixa diferenciação regional, de acordo com as Regiões Administrativas - RAs. Em 1995 mais da metade dos municípios das Regiões Metropolitanas de São Paulo - RMSP e da Baixada Santista - RMBS utilizou-os, sendo também expressiva a participação nas RAs de Campinas (46\% dos municípios) e Bauru (45\% dos municípios). Em 1999, mais da metade dos municípios da RMBS e RMSP e das RAs de Campinas, Ribeirão Preto, São José do Rio Preto, Sorocaba, São José dos Campos e Bauru utilizavam algum tipo de incentivo. Nas demais regiões, a parcela de municípios que o utilizavam também se mostrou elevada. Estes resultados indicam que os incentivos fiscais são intensamente utilizados em todas as regiões do Estado, conforme pode ser observado na Tabela 2 e no Mapa 1.

A existência de Distritos Industriais - DI, em muitos municípios, é componente importante do programa de in- centivos municipais, e a oferta de subsídios, às vezes, está condicionada à instalação do empreendimento nos limites do Distrito. Entre 1995 e 1999, ampliou-se de 24\% para $36 \%$ a parcela de municípios que possuía DI regulamentado.

Até 1995, os DIs existiam principalmente em municípios de médio e grande portes. Entre os municípios com mais de 50 mil habitantes, mais de $40 \%$ o possuíam, enquanto naqueles com até 5 mil habitantes apenas 7\% (11, em 167 municípios). Em 1999, a maior freqüência de DI foi verificada nos municípios da faixa populacional compreendida entre 20 mil e 50 mil habitantes. Houve variações significativas na participação dos municípios com até 5 mil habitantes, cuja parcela de municípios com DI aumentou de 7\% para 19\% entre 1995 e 1999 . Nos municípios com mais de 500 mil habitantes, a participação dos municípios com Distrito Industrial caiu de 50\% em 1995 para $25 \%$ em 1999. O número absoluto de Distritos aumentou de 208 unidades para 347, no período (Tabelas 3 e 4 ).

TABELA 2

Municípios com Mecanismos de Incentivo à Implantação de Empreendimento Estado de São Paulo - 1995-1999

\begin{tabular}{|c|c|c|c|c|c|c|}
\hline \multirow{3}{*}{$\begin{array}{l}\text { Regiões Administrativas e } \\
\text { Regiões Metropolitanas }\end{array}$} & \multicolumn{2}{|c|}{ Número de Municípios } & \multicolumn{4}{|c|}{ Mecanismos de Incentivo à Implantação de Empreendimentos } \\
\hline & \multirow{2}{*}{1995} & \multirow{2}{*}{1999} & \multicolumn{2}{|c|}{1995} & \multicolumn{2}{|c|}{1999} \\
\hline & & & Possui & $\%$ & Possui & $\%$ \\
\hline Total & 625 & 645 & 231 & 37 & 329 & 51 \\
\hline RA de Araçatuba & 40 & 43 & 14 & 35 & 19 & 44 \\
\hline RA de Barretos & 19 & 19 & 3 & 16 & 8 & 42 \\
\hline RA de Bauru & 38 & 39 & 17 & 45 & 21 & 54 \\
\hline RA de Campinas & 90 & 90 & 41 & 46 & 56 & 62 \\
\hline RA Central & 24 & 26 & 8 & 33 & 11 & 42 \\
\hline RA de Franca & 23 & 23 & 7 & 30 & 11 & 48 \\
\hline RA de Marília & 48 & 51 & 18 & 38 & 16 & 31 \\
\hline RA de Presidente Prudente & 51 & 53 & 17 & 33 & 22 & 42 \\
\hline RA de Registro & 14 & 14 & 3 & 21 & 4 & 29 \\
\hline RA de Ribeirão Preto & 23 & 25 & 7 & 30 & 14 & 56 \\
\hline RM da Baixada Santista & 9 & 9 & 5 & 56 & 6 & 67 \\
\hline RM de São Paulo & 39 & 39 & 20 & 51 & 26 & 67 \\
\hline RA de São José do Rio Preto & 92 & 96 & 31 & 34 & 53 & 55 \\
\hline RA de São José dos Campos & 38 & 39 & 12 & 32 & 20 & 51 \\
\hline RA de Sorocaba & 77 & 79 & 28 & 36 & 42 & 53 \\
\hline
\end{tabular}

Fonte: Fundação Seade. Pesquisa Municipal Unificada - PMU. 


\section{MAPA 1}

Existência de Distritos Industriais

1999

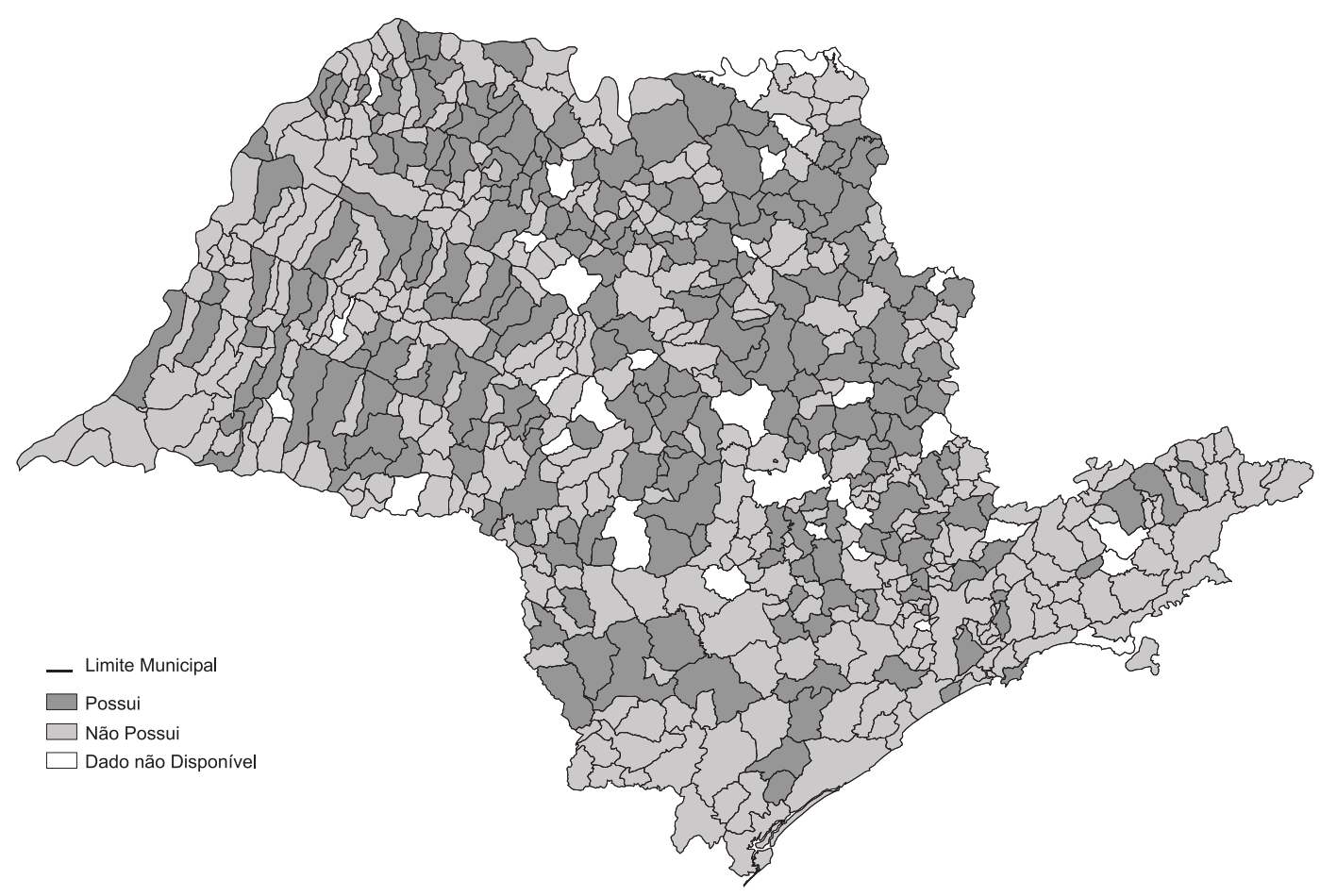

Fonte: Fundação Seade. Pesquisa Municipal Unificada - PMU.

TABELA 3

Municípios com Distritos Industriais Regulamentados, segundo Porte Populacional Estado de São Paulo - 1995-1999

\begin{tabular}{|c|c|c|c|c|c|c|c|c|c|c|c|c|c|c|c|c|}
\hline \multirow{3}{*}{ População } & \multicolumn{2}{|c|}{$\begin{array}{l}\text { Número de } \\
\text { Municípios }\end{array}$} & \multicolumn{4}{|c|}{$\begin{array}{l}\text { Existência de Distrito } \\
\text { Industrial Regulamentado }\end{array}$} & \multicolumn{2}{|c|}{$\begin{array}{l}\text { Número de Distritos } \\
\text { Industriais }\end{array}$} & \multicolumn{4}{|c|}{ Cessão de Terrenos } & \multicolumn{4}{|c|}{ Doação de Terrenos } \\
\hline & \multirow{2}{*}{1995} & \multirow{2}{*}{1999} & \multicolumn{2}{|c|}{1995} & \multicolumn{2}{|c|}{1999} & \multirow{2}{*}{1995} & \multirow{2}{*}{1999} & \multicolumn{2}{|c|}{1995} & \multicolumn{2}{|c|}{1999} & \multicolumn{2}{|c|}{1995} & \multicolumn{2}{|c|}{1999} \\
\hline & & & Possui & $\%$ & Possui & $\%$ & & & Possui & $\%$ & Possui & $\%$ & Possui & $\%$ & Possui & $\%$ \\
\hline Total & 625 & 645 & 153 & 24 & 229 & 36 & 208 & 347 & 96 & 15 & 152 & 24 & 150 & 24 & 195 & 30 \\
\hline Até 5 Mil Hab. & 167 & 180 & 11 & 7 & 34 & 19 & 12 & 35 & 16 & 10 & 41 & 23 & 27 & 16 & 41 & 23 \\
\hline Mais de 5 Mil a 10 Mil Hab. & 120 & 116 & 19 & 16 & 31 & 27 & 21 & 37 & 14 & 12 & 23 & 20 & 25 & 21 & 32 & 28 \\
\hline Mais de 10 Mil a 20 Mil Hab. & 119 & 117 & 31 & 6 & 47 & 40 & 31 & 64 & 17 & 14 & 32 & 27 & 29 & 24 & 45 & 38 \\
\hline Mais de 20 Mil a 50 Mil Hab. & 116 & 117 & 45 & 39 & 65 & 56 & 57 & 94 & 20 & 17 & 36 & 31 & 36 & 31 & 44 & 38 \\
\hline Mais de 50 Mil a 100 Mil Hab. & 50 & 53 & 23 & 46 & 26 & 49 & 37 & 51 & 17 & 34 & 17 & 32 & 19 & 38 & 21 & 40 \\
\hline Mais de 100 Mil a 250 Mil Hab. & 33 & 40 & 15 & 45 & 18 & 45 & 34 & 56 & 8 & 24 & 3 & 8 & 10 & 30 & 11 & 28 \\
\hline Mais de 250 Mil a 500 Mil Hab. & 14 & 14 & 6 & 43 & 6 & 43 & 11 & 6 & 3 & 21 & 0 & 0 & 3 & 21 & 1 & 7 \\
\hline Mais de 500 Mil Hab. & 6 & 8 & 3 & 50 & 2 & 25 & 5 & 4 & 1 & 17 & 0 & 0 & 1 & 17 & 0 & 0 \\
\hline
\end{tabular}

Fonte: Fundação Seade. Pesquisa Municipal Unificada - PMU. 


\section{TABELA 4}

Municípios com Distritos Industriais Regulamentados Estado de São Paulo - 1995-1999

\begin{tabular}{|c|c|c|c|c|c|c|c|c|c|c|c|c|c|c|c|c|}
\hline \multirow{3}{*}{$\begin{array}{l}\text { Regiões Administrativas e } \\
\text { Regiões Metropolitanas }\end{array}$} & \multicolumn{2}{|c|}{$\begin{array}{l}\text { Número de } \\
\text { Municípios }\end{array}$} & \multicolumn{4}{|c|}{$\begin{array}{c}\text { Existência de Distrito } \\
\text { Industrial Regulamentado }\end{array}$} & \multicolumn{2}{|c|}{$\begin{array}{l}\text { Número de Distritos } \\
\text { Industriais }\end{array}$} & \multicolumn{4}{|c|}{ Cessão de Terrenos } & \multicolumn{4}{|c|}{ Doação de Terrenos } \\
\hline & \multirow{2}{*}{1995} & \multirow{2}{*}{1999} & \multicolumn{2}{|c|}{1995} & \multicolumn{2}{|c|}{1999} & \multirow{2}{*}{1995} & \multirow{2}{*}{1999} & \multicolumn{2}{|c|}{1995} & \multicolumn{2}{|l|}{1999} & \multicolumn{2}{|c|}{1995} & \multicolumn{2}{|c|}{1999} \\
\hline & & & Possui & $\%$ & Possui & $\%$ & & & Possui & $\%$ & Possui & $\%$ & Possui & $\%$ & Possui & $\%$ \\
\hline Total & 625 & 645 & 153 & 24 & 229 & 36 & 208 & 347 & 96 & 15 & 152 & 24 & 150 & 24 & 195 & 30 \\
\hline RA de Araçatuba & 40 & 43 & 6 & 15 & 11 & 26 & 8 & 16 & 8 & 20 & 12 & 28 & 10 & 25 & 11 & 26 \\
\hline RA de Barretos & 19 & 19 & 4 & 21 & 7 & 37 & 5 & 12 & 1 & 5 & 7 & 37 & 3 & 16 & 6 & 32 \\
\hline RA de Bauru & 38 & 39 & 14 & 37 & 18 & 46 & 18 & 30 & 11 & 29 & 17 & 44 & 14 & 37 & 16 & 41 \\
\hline RA de Campinas & 90 & 90 & 24 & 27 & 37 & 41 & 35 & 61 & 11 & 12 & 17 & 19 & 17 & 19 & 25 & 28 \\
\hline RA Central & 24 & 26 & 7 & 29 & 12 & 46 & 11 & 23 & 4 & 17 & 5 & 19 & 7 & 29 & 8 & 31 \\
\hline RA de Franca & 23 & 23 & 8 & 35 & 9 & 39 & 7 & 9 & 1 & 4 & 7 & 30 & 5 & 22 & 8 & 35 \\
\hline RA de Marília & 48 & 51 & 9 & 19 & 19 & 37 & 14 & 29 & 8 & 17 & 7 & 14 & 13 & 27 & 10 & 20 \\
\hline RA de Presidente Prudente & 51 & 53 & 14 & 27 & 13 & 25 & 20 & 16 & 8 & 16 & 13 & 25 & 14 & 27 & 17 & 32 \\
\hline RA de Registro & 14 & 14 & 4 & 29 & 3 & 21 & 4 & 4 & 1 & 7 & 2 & 14 & 3 & 21 & 1 & 7 \\
\hline RA de Ribeirão Preto & 23 & 25 & 7 & 30 & 15 & 60 & 7 & 22 & 4 & 17 & 8 & 32 & 3 & 13 & 8 & 32 \\
\hline RM da Baixada Santista & 9 & 9 & 1 & 11 & 2 & 22 & 1 & 2 & 0 & 0 & 1 & 11 & 0 & 0 & 0 & 0 \\
\hline RM de São Paulo & 39 & 39 & 7 & 18 & 8 & 21 & 9 & 11 & 6 & 15 & 1 & 3 & 5 & 13 & 2 & 5 \\
\hline RA de São José do Rio Preto & 92 & 96 & 23 & 25 & 44 & 46 & 40 & 70 & 12 & 13 & 28 & 29 & 28 & 30 & 41 & 43 \\
\hline RA de São José dos Campos & 38 & 39 & 7 & 18 & 4 & 10 & 8 & 7 & 5 & 13 & 6 & 15 & 8 & 21 & 14 & 36 \\
\hline RA de Sorocaba & 77 & 79 & 18 & 23 & 27 & 34 & 21 & 35 & 16 & 21 & 21 & 27 & 20 & 26 & 28 & 35 \\
\hline
\end{tabular}

Fonte: Fundação Seade. Pesquisa Municipal Unificada - PMU.

MAPA 2

Mecanismo de Incentivo

1999

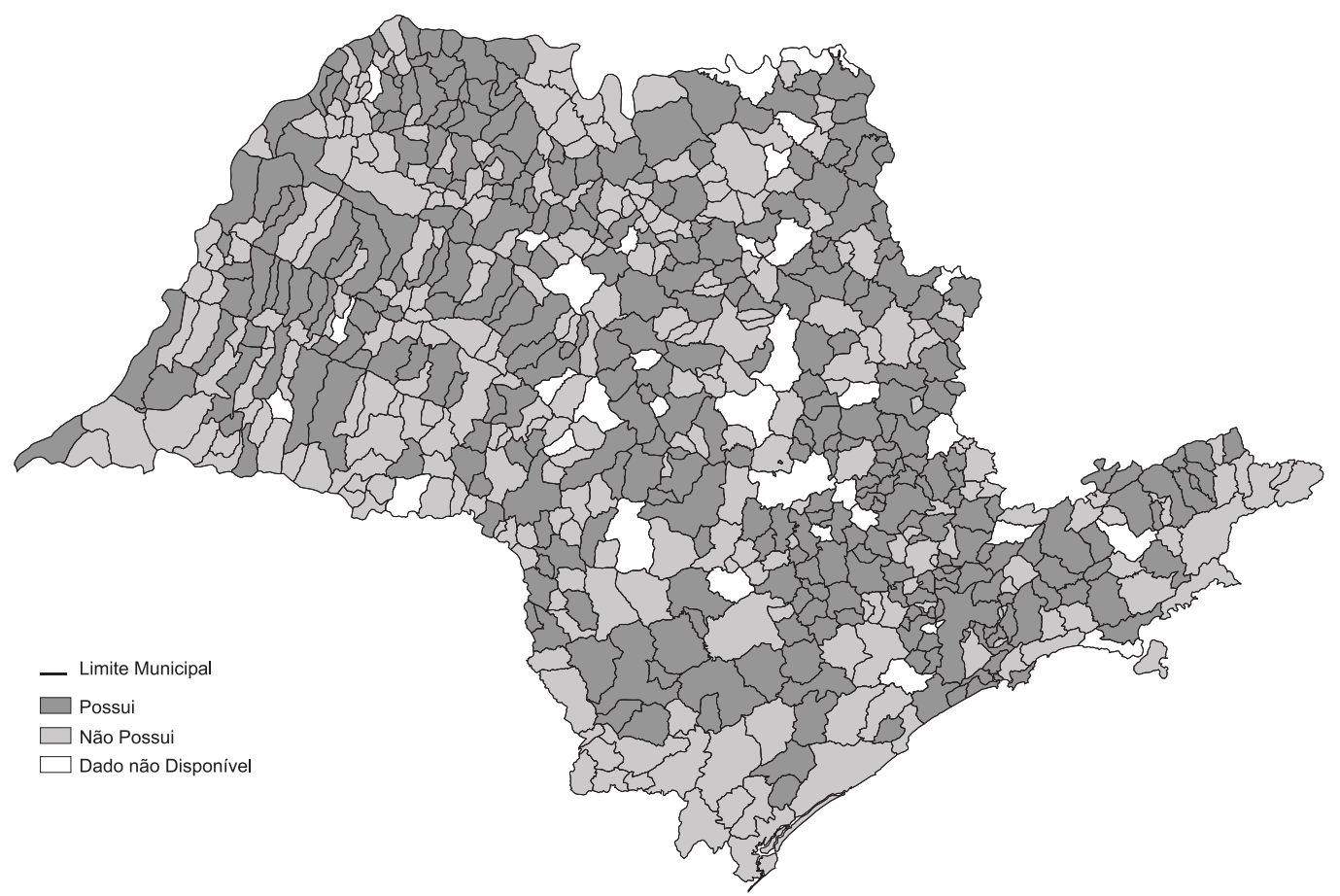

Fonte: Fundação Seade. Pesquisa Municipal Unificada - PMU. 
Em 1999, mais de 40\% dos municípios das RAs de Bauru, Campinas, Central, Ribeirão Preto e São José do Rio Preto possuíam DI. Neste ano, a menor participação foi verificada na RA de São José dos Campos, com 10\% dos municípios, principalmente pela ausência nos municípios das Regiões de Governo de Caraguatatuba e Cruzeiro (Mapa 2).

As isenções podem envolver a totalidade ou uma parcela do imposto. No segundo caso, a porcentagem isenta do tributo varia entre $1 \%$ e $80 \%$.

Em 1995, 27\% dos municípios paulistas isentavam totalmente do pagamento do Imposto Predial e Territorial Urbano - IPTU dos novos investimentos. Essa participação aumentou para $36 \%$ em 1999, e, nos municípios com mais de 50 mil habitantes, mais de $50 \%$. O prazo de isenção total do IPTU tem sido de até 35 anos. Observa-se, no entanto, que a isenção parcial do IPTU é pouco utilizada. Também neste caso se verifica que os municípios maiores utilizavam mais intensivamente o benefício (Tabela 5).

Mais de 30\% dos municípios das RAs de Bauru, Campinas, RMBS e RMSP ofereciam isenção total de IPTU em 1995. As três primeiras regiões também usavam mais intensivamente as isenções parciais de IPTU, em mais de 10\% de seus municípios. Em 1999, os municípios das RAs de Bauru, Campinas, Ribeirão Preto e RMBS continuavam sendo, proporcionalmente, os principais ofertantes de isenção total de IPTU.
As informações sobre concessão de incentivo pela isenção do Imposto sobre Serviços de Qualquer Natureza ISS estão disponíveis, na PMU, somente para 1999, e indicam que $29 \%$ dos municípios a concediam. As maiores ocorrências foram verificadas nos municípios com mais de 500 mil habitantes e na RMBS, RMSP, RA de Campinas e RA de Franca. Também eram significativas as parcelas dos municípios das RAs de São José dos Campos e Sorocaba (Tabela 6).

A isenção de taxas municipais é uma prática de incentivo que vem-se ampliando, ocorrendo em $20 \%$ dos municípios, em 1995, e em 30\%, em 1999. O tempo de fruição desse benefício varia de um a 20 anos. Tanto em 1995 quanto em 1999, os municípios com população superior a 50 mil habitantes utilizavam mais intensamente este instrumento, e a menor freqüência residia no grupo com menos de 5 mil habitantes.

Quanto à distribuição regional, em 1995, mais de 25\% dos municípios da RA de Campinas e da RMSP isentavam de taxas municipais os novos empreendimentos. Em 1999, as Regiões Administrativas que mais aplicaram esse recurso foram: Barretos, Campinas, Sorocaba, São José dos Campos e RMSP. Observa-se que em 1995 nenhum município da RMBS lançou mão desse benefício e, em 1999, quatro o concediam (44\% dos municípios dessa região).

TABELA 5

Municípios que Oferecem Isenção Total e Parcial de IPTU, segundo Porte Populacional Estado de São Paulo - 1995-1999

\begin{tabular}{|c|c|c|c|c|c|c|c|c|c|c|c|c|c|c|c|c|}
\hline \multirow{3}{*}{ População } & \multicolumn{2}{|c|}{$\begin{array}{l}\text { Número de } \\
\text { Municípios }\end{array}$} & \multicolumn{4}{|c|}{$\begin{array}{l}\text { Isenção Total } \\
\text { de IPTU }\end{array}$} & \multicolumn{4}{|c|}{$\begin{array}{l}\text { Isenção Parcial } \\
\text { de IPTU }\end{array}$} & \multirow{2}{*}{\multicolumn{2}{|c|}{$\frac{\text { Isenção de ISS }}{1999}$}} & \multicolumn{4}{|c|}{ Isenção de Taxas } \\
\hline & \multirow{2}{*}{1995} & \multirow{2}{*}{1999} & \multicolumn{2}{|c|}{1995} & \multicolumn{2}{|c|}{1999} & \multicolumn{2}{|c|}{1995} & \multicolumn{2}{|c|}{1999} & & & \multicolumn{2}{|l|}{1995} & \multicolumn{2}{|l|}{1999} \\
\hline & & & Possui & $\%$ & Possui & $\%$ & Possui & $\%$ & Possui & $\%$ & Possui & $\%$ & Possui & $\%$ & Possui & $\%$ \\
\hline Total & 625 & 645 & 168 & 27 & 235 & 36 & 46 & 7 & 56 & 9 & 190 & 29 & 124 & 20 & 194 & 30 \\
\hline Até 5 Mil Hab. & 167 & 180 & 24 & 14 & 47 & 26 & 7 & 4 & 8 & 4 & 38 & 21 & 20 & 12 & 35 & 19 \\
\hline Mais de 5 Mil a 10 Mil Hab. & 120 & 116 & 22 & 18 & 31 & 27 & 8 & 7 & 6 & 5 & 26 & 22 & 19 & 16 & 32 & 28 \\
\hline Mais de 10 Mil a 20 Mil Hab. & 119 & 117 & 28 & 24 & 44 & 38 & 9 & 8 & 10 & 9 & 34 & 29 & 16 & 13 & 32 & 27 \\
\hline Mais de 20 Mil a 50 Mil Hab. & 116 & 117 & 41 & 35 & 48 & 41 & 8 & 7 & 17 & 15 & 35 & 30 & 28 & 24 & 40 & 34 \\
\hline Mais de 50 Mil a 100 Mil Hab. & 50 & 53 & 27 & 54 & 30 & 57 & 4 & 8 & 4 & 8 & 26 & 49 & 23 & 46 & 30 & 57 \\
\hline Mais de 100 Mil a 250 Mil Hab. & 33 & 40 & 19 & 58 & 24 & 60 & 6 & 18 & 6 & 15 & 20 & 50 & 15 & 45 & 19 & 48 \\
\hline Mais de 250 Mil a 500 Mil Hab. & 14 & 14 & 5 & 36 & 7 & 50 & 2 & 14 & 2 & 14 & 5 & 36 & 2 & 14 & 4 & 29 \\
\hline Mais de 500 Mil Hab. & 6 & 8 & 2 & 33 & 4 & 50 & 2 & 33 & 3 & 38 & 6 & 75 & 1 & 17 & 2 & 25 \\
\hline
\end{tabular}

Fonte: Fundação Seade. Pesquisa Municipal Unificada - PMU. 
TABELA 6

Municípios que Oferecem Isenção Total e Parcial de IPTU

Estado de São Paulo - 1995-1999

\begin{tabular}{|c|c|c|c|c|c|c|c|c|c|c|c|c|c|c|c|c|}
\hline \multirow{3}{*}{$\begin{array}{l}\text { Regiões Administrativas e } \\
\text { Regiões Metropolitanas }\end{array}$} & \multicolumn{2}{|c|}{$\begin{array}{l}\text { Número de } \\
\text { Municípios }\end{array}$} & \multicolumn{4}{|c|}{$\begin{array}{l}\text { Isenção Total } \\
\text { de IPTU }\end{array}$} & \multicolumn{4}{|c|}{$\begin{array}{l}\text { Isenção Parcial } \\
\text { de IPTU }\end{array}$} & \multirow{2}{*}{\multicolumn{2}{|c|}{$\frac{\text { Isenção de ISS }}{1999}$}} & \multicolumn{4}{|c|}{ Isenção de Taxas } \\
\hline & \multirow{2}{*}{1995} & \multirow{2}{*}{1999} & \multicolumn{2}{|c|}{1995} & \multicolumn{2}{|c|}{1999} & \multicolumn{2}{|c|}{1995} & \multicolumn{2}{|c|}{1999} & & & \multicolumn{2}{|l|}{1995} & \multicolumn{2}{|l|}{1999} \\
\hline & & & Possui & $\%$ & Possui & $\%$ & Possui & $\%$ & Possui & $\%$ & Possui & $\%$ & Possui & $\%$ & Possui & $\%$ \\
\hline Total & 625 & 645 & 168 & 27 & 235 & 36 & 46 & 7 & 56 & 9 & 190 & 29 & 124 & 20 & 194 & 30 \\
\hline RA de Araçatuba & 40 & 43 & 10 & 25 & 14 & 33 & 2 & 5 & 1 & 2 & 8 & 19 & 10 & 25 & 12 & 28 \\
\hline RA de Barretos & 19 & 19 & 1 & 5 & 6 & 32 & 0 & 0 & 1 & 5 & 6 & 32 & 1 & 5 & 8 & 42 \\
\hline RA de Bauru & 38 & 39 & 13 & 34 & 19 & 49 & 5 & 13 & 2 & 5 & 12 & 31 & 9 & 24 & 13 & 33 \\
\hline RA de Campinas & 90 & 90 & 31 & 34 & 43 & 48 & 8 & 9 & 6 & 7 & 35 & 39 & 25 & 28 & 35 & 39 \\
\hline RA Central & 24 & 26 & 7 & 29 & 6 & 23 & 2 & 8 & 2 & 8 & 5 & 19 & 4 & 17 & 3 & 12 \\
\hline RA de Franca & 23 & 23 & 6 & 26 & 9 & 39 & 1 & 4 & 2 & 9 & 9 & 39 & 4 & 17 & 6 & 26 \\
\hline RA de Marília & 48 & 51 & 14 & 29 & 5 & 10 & 1 & 2 & 4 & 8 & 6 & 12 & 10 & 21 & 8 & 16 \\
\hline RA de Presidente Prudente & 51 & 53 & 10 & 20 & 17 & 32 & 2 & 4 & 2 & 4 & 12 & 23 & 6 & 12 & 14 & 26 \\
\hline RA de Registro & 14 & 14 & 3 & 21 & 4 & 29 & 0 & 0 & 2 & 14 & 0 & 0 & 2 & 14 & 1 & 7 \\
\hline RA de Ribeirão Preto & 23 & 25 & 4 & 17 & 11 & 44 & 3 & 13 & 3 & 12 & 6 & 24 & 4 & 17 & 7 & 28 \\
\hline RM da Baixada Santista & 9 & 9 & 4 & 44 & 5 & 56 & 1 & 11 & 2 & 22 & 5 & 56 & 0 & 0 & 4 & 44 \\
\hline RM de São Paulo & 39 & 39 & 14 & 36 & 14 & 36 & 8 & 21 & 9 & 23 & 19 & 49 & 10 & 26 & 14 & 36 \\
\hline RA de São José do Rio Preto & 92 & 96 & 21 & 23 & 36 & 38 & 6 & 7 & 6 & 6 & 28 & 29 & 15 & 16 & 26 & 27 \\
\hline RA de São José dos Campos & 38 & 39 & 8 & 21 & 15 & 38 & 2 & 5 & 6 & 15 & 13 & 33 & 8 & 21 & 14 & 36 \\
\hline RA de Sorocaba & 77 & 79 & 22 & 29 & 31 & 39 & 5 & 6 & 8 & 10 & 26 & 33 & 16 & 21 & 29 & 37 \\
\hline
\end{tabular}

Fonte: Fundação Seade. Pesquisa Municipal Unificada - PMU.

A Doação de Terrenos tem sido outro instrumento bastante utilizado. Em 1995, 24\% dos municípios doavam. Esta parcela aumentou para 30\%, em 1999. No entanto, esse incentivo não foi adotado em municípios de grande porte, ou seja, com mais de 500 mil habitantes. Outro recurso utilizado, nesse mesmo período, foi a Cessão de Terrenos, mas não por municípios com mais de 250 mil habitantes.

Em 1995, mais de 20\% dos municípios das RAs de Bauru e de Sorocaba cediam terrenos a novos empreendimentos. A doação era utilizada por 37\% dos municípios da RA de Bauru e 30\% dos municípios da RA de São José do Rio Preto, naquele ano. Em 1999, a Cessão de Terrenos era, sobretudo, utilizada pelos municípios das RAs de Bauru, Barretos e Ribeirão Preto e a Doação de Terrenos, pelas RAs de São José do Rio Preto, Bauru e São José dos Campos. Nesse mesmo ano, destaca-se a baixa participação dos municípios da RMBS, RMSP e RA de Registro, no uso desse instrumento como atrativo de novos investimentos.

Essas observações sugerem que a doação e a cessão de terrenos têm sido utilizadas, em especial, por municípios mais afastados da RMSP, à exceção da RA de Sorocaba onde significativa parcela dos municípios dispunha desses dois mecanismos de incentivo nos dois anos considerados.

Além de dispor de mecanismos de incentivo e apoio a novos investimentos, os municípios também recorrem, com menor intensidade, aos mecanismos de restrição à edificação de empreendimentos. Procuram evitar, de alguma forma, os investimentos que agridam o meio ambiente. Em 1999, 17\% dos municípios mantinham esse cuidado. A maior ocorrência foi verificada nos municípios com população superior a 50 mil habitantes. Contrariamente, nos municípios com menos de 5 mil habitantes (180 municípios), apenas dez declararam utilizar algum mecanismo de restrição à instauração de empreendimentos em 1999, o que representa apenas $6 \%$ dos municípios dessa faixa. Os municípios que mais adotam tal restrição estão nas RAs de Campinas, Ribeirão Preto, RMBS, RMSP, São José dos Campos e Sorocaba (Tabelas 7 e 8).

Entre os mecanismos de restrição à instauração de novos empreendimentos, a PMU permitiu observar que a legislação municipal é mais utilizada do que a tributação. Em 1999, 15\% dos municípios do Estado declararam utilizar a legislação como mecanismo de restrição, principalmente os municípios com mais de 50 mil habitantes. Já os municípios com população superior a 500 mil habitantes, $63 \%$ deles utilizam esse tipo de legislação específica. $\mathrm{Na}$ adoção desse sistema, destacam-se as RAs de Campinas, RMBS e RMSP (Mapa 3).

A tributação municipal, como instrumento de restrição à implantação de empreendimentos, não só é pouco 
TABELA 7

Municípios com Mecanismos de Restrição à Implantação de Empreendimentos, segundo Porte Populacional Estado de São Paulo - 1995-1999

\begin{tabular}{|c|c|c|c|c|c|c|c|c|c|c|c|c|c|c|c|c|c|c|}
\hline \multirow[t]{3}{*}{ População } & \multicolumn{2}{|c|}{$\begin{array}{l}\text { Número de } \\
\text { Municípios }\end{array}$} & \multicolumn{4}{|c|}{$\begin{array}{l}\text { Mecanismos de Restrição } \\
\text { à Implantação de } \\
\text { Empreendimentos }\end{array}$} & \multicolumn{4}{|c|}{$\begin{array}{l}\text { Utilização de Legislação } \\
\text { como Restrição à } \\
\text { Implantação de } \\
\text { Empreendimentos }\end{array}$} & \multicolumn{4}{|c|}{$\begin{array}{l}\text { Utilização de Tributação } \\
\text { como Restrição à } \\
\text { Implantação de } \\
\text { Empreendimentos }\end{array}$} & \multicolumn{4}{|c|}{$\begin{array}{l}\text { Mecanismo de Restrição à } \\
\text { Implantação de Indústria } \\
\text { Poluidora }\end{array}$} \\
\hline & \multirow[t]{2}{*}{1995} & \multirow[t]{2}{*}{1999} & \multicolumn{2}{|c|}{1995} & \multicolumn{2}{|l|}{1999} & \multicolumn{2}{|c|}{1995} & \multicolumn{2}{|c|}{1999} & \multicolumn{2}{|c|}{1995} & \multicolumn{2}{|l|}{1999} & \multicolumn{2}{|c|}{1995} & \multicolumn{2}{|c|}{1999} \\
\hline & & & Possui & $\%$ & Possui & $\%$ & Possui & $\%$ & Possui & $\%$ & Possui & $\%$ & Possui & $\%$ & Possui & $\%$ & Possui & $\%$ \\
\hline Total & 625 & 645 & 108 & 17 & 108 & 17 & 93 & 15 & 95 & 15 & 8 & 1 & 6 & 1 & 104 & 17 & 97 & 15 \\
\hline Até 5 Mil Hab. & 167 & 180 & 11 & 7 & 10 & 6 & 9 & 5 & 8 & 4 & 0 & 0 & 1 & 1 & 11 & 7 & 10 & 6 \\
\hline Mais de 5 Mil a 10 Mil Hab. & 120 & 116 & 13 & 11 & 12 & 10 & 9 & 8 & 11 & 9 & 1 & 1 & 0 & 0 & 11 & 9 & 12 & 10 \\
\hline Mais de 10 Mil a 20 Mil Hab. & 119 & 117 & 11 & 9 & 18 & 15 & 9 & 8 & 15 & 13 & 0 & 0 & 1 & 1 & 10 & 8 & 14 & 12 \\
\hline Mais de 20 Mil a 50 Mil Hab. & 116 & 117 & 26 & 22 & 19 & 16 & 23 & 20 & 15 & 13 & 2 & 2 & 0 & 0 & 26 & 22 & 16 & 14 \\
\hline Mais de 50 Mil a 100 Mil Hab. & 50 & 53 & 26 & 52 & 19 & 36 & 23 & 46 & 19 & 36 & 3 & 6 & 2 & 4 & 26 & 52 & 16 & 30 \\
\hline Mais de 100 Mil a 250 Mil Hab. & 33 & 40 & 11 & 33 & 19 & 48 & 10 & 30 & 17 & 43 & 0 & 0 & 1 & 3 & 10 & 30 & 19 & 48 \\
\hline Mais de 250 Mil a 500 Mil Hab. & 14 & 14 & 6 & 43 & 6 & 43 & 6 & 43 & 5 & 36 & 1 & 7 & 1 & 7 & 6 & 43 & 5 & 36 \\
\hline Mais de 500 Mil Hab. & 6 & 8 & 4 & 67 & 5 & 63 & 4 & 67 & 5 & 63 & 1 & 17 & 0 & 0 & 4 & 67 & 5 & 63 \\
\hline
\end{tabular}

Fonte: Fundação Seade. Pesquisa Municipal Unificada - PMU.

TABELA 8

Municípios com Mecanismos de Restrição à Implantação de Empreendimentos Estado de São Paulo - 1995-1999

\begin{tabular}{|c|c|c|c|c|c|c|c|c|c|c|c|c|c|c|c|c|c|c|}
\hline \multirow[t]{3}{*}{$\begin{array}{l}\text { Regiões Administrativas e } \\
\text { Regiões Metropolitanas }\end{array}$} & \multicolumn{2}{|c|}{$\begin{array}{l}\text { Número de } \\
\text { Municípios }\end{array}$} & \multicolumn{4}{|c|}{$\begin{array}{l}\text { Mecanismos de Restrição } \\
\text { à Implantação de } \\
\text { Empreendimentos }\end{array}$} & \multicolumn{4}{|c|}{$\begin{array}{l}\text { Utilização de Legislação } \\
\text { como Restrição à } \\
\text { Implantação de } \\
\text { Empreendimentos }\end{array}$} & \multicolumn{4}{|c|}{$\begin{array}{l}\text { Utilização de Tributação } \\
\text { como Restrição à } \\
\text { Implantação de } \\
\text { Empreendimentos }\end{array}$} & \multicolumn{4}{|c|}{$\begin{array}{l}\text { Mecanismo de Restrição à } \\
\text { Implantação de Indústria } \\
\text { Poluidora }\end{array}$} \\
\hline & \multirow[t]{2}{*}{1995} & \multirow[t]{2}{*}{1999} & \multicolumn{2}{|c|}{1995} & \multicolumn{2}{|l|}{1999} & \multicolumn{2}{|c|}{1995} & \multicolumn{2}{|c|}{1999} & \multicolumn{2}{|l|}{1995} & \multicolumn{2}{|l|}{1999} & \multicolumn{2}{|c|}{1995} & \multicolumn{2}{|c|}{1999} \\
\hline & & & Possui & $\%$ & Possui & $\%$ & Possui & $\%$ & Possui & $\%$ & Possui & $\%$ & Possui & $\%$ & Possui & $\%$ & Possui & $\%$ \\
\hline Total & 625 & 645 & 108 & 17 & 108 & 17 & 93 & 15 & 94 & 15 & 8 & 1 & 6 & 1 & 104 & 17 & 97 & 15 \\
\hline RA de Araçatuba & 40 & 43 & 3 & 8 & 2 & 5 & 2 & 5 & 2 & 5 & 0 & 0 & 1 & 2 & 3 & 8 & 2 & 5 \\
\hline RA de Barretos & 19 & 19 & 0 & 0 & 2 & 11 & 0 & 0 & 2 & 11 & 0 & 0 & 1 & 5 & 0 & 0 & 2 & 11 \\
\hline RA de Bauru & 38 & 39 & 2 & 5 & 2 & 5 & 2 & 5 & 2 & 5 & 0 & 0 & 0 & 0 & 2 & 5 & 2 & 5 \\
\hline RA de Campinas & 90 & 90 & 31 & 34 & 34 & 38 & 27 & 30 & 30 & 33 & 0 & 0 & 0 & 0 & 28 & 31 & 31 & 34 \\
\hline RA Central & 24 & 26 & 1 & 4 & 1 & 4 & 1 & 4 & 1 & 4 & 0 & 0 & 0 & 0 & 1 & 4 & 1 & 4 \\
\hline RA de Franca & 23 & 23 & 1 & 4 & 1 & 4 & 1 & 4 & 1 & 4 & 0 & 0 & 0 & 0 & 1 & 4 & 1 & 4 \\
\hline RA de Marília & 48 & 51 & 5 & 10 & 2 & 4 & 4 & 8 & 2 & 4 & 0 & 0 & 0 & 0 & 5 & 10 & 2 & 4 \\
\hline RA de Presidente Prudente & 51 & 53 & 5 & 10 & 3 & 6 & 4 & 8 & 3 & 6 & 1 & 2 & 0 & 0 & 4 & 8 & 2 & 4 \\
\hline RA de Registro & 14 & 14 & 2 & 14 & 1 & 7 & 2 & 14 & 1 & 7 & 0 & 0 & 0 & 0 & 2 & 14 & 1 & 7 \\
\hline RA de Ribeirão Preto & 23 & 25 & 4 & 17 & 7 & 28 & 3 & 13 & 5 & 20 & 0 & 0 & 0 & 0 & 4 & 17 & 5 & 20 \\
\hline RM da Baixada Santista & 9 & 9 & 4 & 44 & 4 & 44 & 4 & 44 & 4 & 44 & 2 & 22 & 1 & 11 & 4 & 44 & 4 & 44 \\
\hline RM de São Paulo & 39 & 39 & 13 & 33 & 16 & 41 & 13 & 33 & 15 & 38 & 2 & 5 & 0 & 0 & 13 & 33 & 13 & 33 \\
\hline RA de São José do Rio Preto & 92 & 96 & 8 & 9 & 8 & 8 & 6 & 7 & 6 & 6 & 0 & 0 & 0 & 0 & 8 & 9 & 8 & 8 \\
\hline RA de São José dos Campos & 38 & 39 & 11 & 29 & 10 & 26 & 10 & 26 & 10 & 26 & 2 & 5 & 1 & 3 & 11 & 29 & 9 & 23 \\
\hline RA de Sorocaba & 77 & 79 & 18 & 23 & 15 & 19 & 14 & 18 & 11 & 14 & 1 & 1 & 2 & 3 & 18 & 23 & 14 & 18 \\
\hline
\end{tabular}

Fonte: Fundação Seade. Pesquisa Municipal Unificada - PMU. 
aplicada no Estado de São Paulo como também é reduzida. Em 1995, apenas 8 dos 625 municípios declararam dispor desse mecanismo: Tarabaí na RA de Presidente Prudente, Cubatão e São Vicente na RMBS, Poá e Guarulhos na RMSP, Taubaté na RA de São José dos Campos e Mairinque na RA de Sorocaba. Em 1999, somente seis municípios recorriam a esse mecanismo: Penápolis na RA de Araçatuba, Avaré e Itapetininga na RA de Sorocaba, São Vicente na RMBS e Caçapava na RA de São José dos Campos.

A proporção de municípios que responderam afirmativamente à questão referente à utilização de mecanismos de restrição à implantação de indústria poluidora declinou ligeiramente durante os anos considerados, passando de 17\% em 1995 para 15\% em 1999.

Estes mecanismos são mais utilizados nos municípios de maior porte, em especial naqueles com população superior a 500 mil habitantes (67\% dos municípios em 1995 e $63 \%$ em 1999). Nesta faixa, apenas os municípios de Ribeirão Preto, Santo André e Osasco não apresentavam mecanismos de restrição à criação de indústrias poluidoras, em 1995 e 1999. A maior intensidade de aplicação desses instrumentos foi observada nas RAs de Campinas, RMBS e RMSP, sendo também significativa em São José dos Campos e Sorocaba, nos dois anos considerados.

A razão para maior concentração da utilização desses mecanismos em municípios com mais de 500 mil habitantes e nas regiões mais industrializadas do Estado é facilmente identificável. É porque esses municípios são industrializados, e em alguns casos com condições ambientais já bastante afetadas, e exigem maior atenção com a deterioração da qualidade de vida.

A instalação de uma unidade de indústria extrativa mineral, como no caso de indústria poluidora, pode comprometer seriamente as condições ambientais, razão pela qual os municípios maiores e mais industrializados têmse mostrado mais preocupados em estabelecer restrições quanto à adoção desse tipo de empreendimento. Entretanto, essa prática é pouco expressiva nos municípios paulistas. Em 1995 apenas 7\%, tendo esta participação aumentado apenas um ponto percentual em 1999. Observa-se, também, que a maior freqüência é de municípios com mais de 500 mil habitantes. Nessa faixa, apenas Ribeirão Preto, Santo André e Osasco não dispunham desse mecanismo.

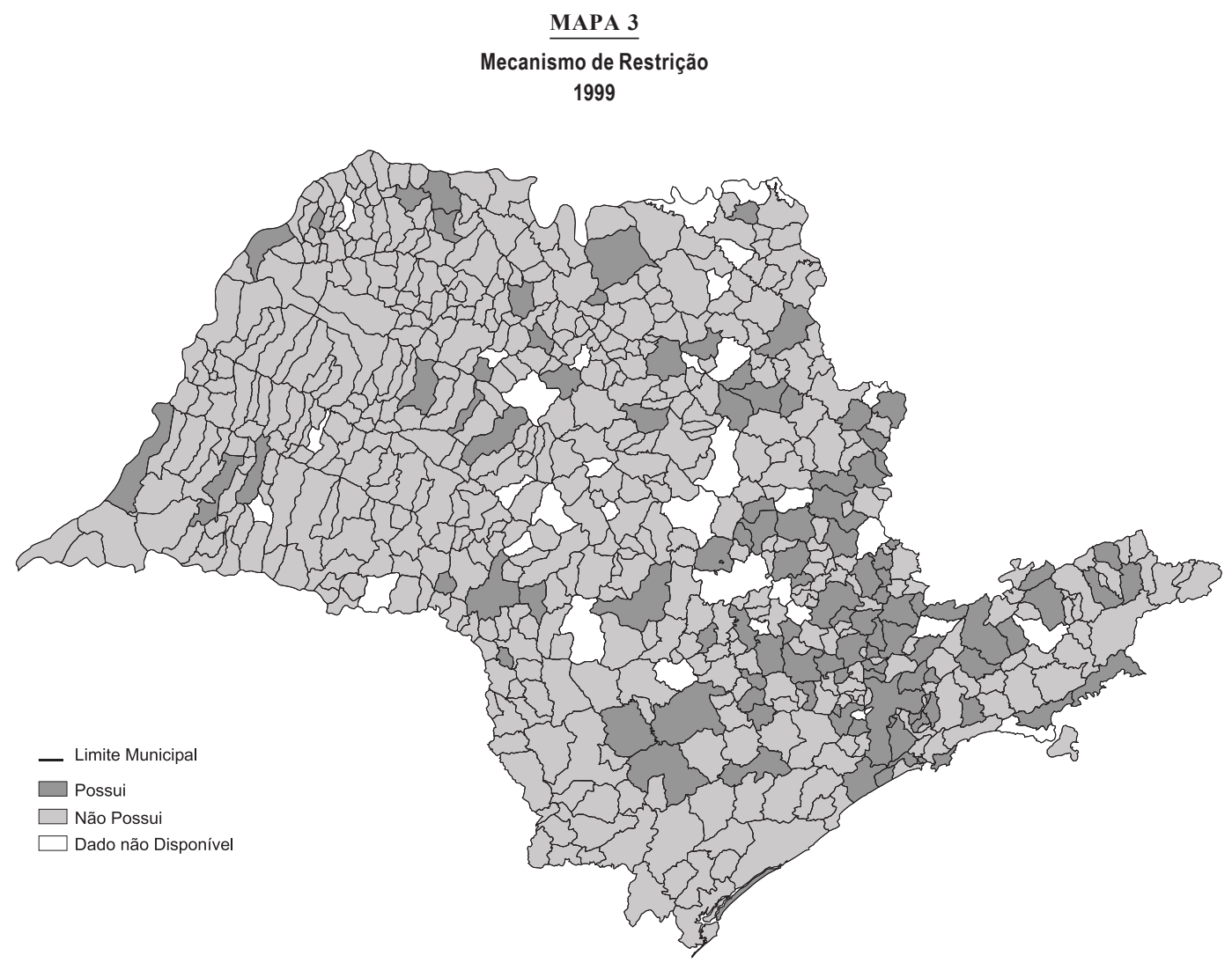

Fonte: Fundação Seade. Pesquisa Municipal Unificada - PMU. 
Em contraste, ele é muito pouco utilizado pelos municípios com menos de 20 mil habitantes. É curioso o fato de que, na faixa até 5 mil habitantes, apenas Águas de São Pedro, Macedônia, Álvares Florence e Tuiuti declararam utilizar esse tipo de instrumento.

Da mesma forma que os instrumentos de restrição à instalação de indústrias poluidoras, as RAs que mais utilizavam esse mecanismo são Campinas, RMBS e RMSP, seguidas pelas RAs de São José dos Campos e Sorocaba.

\section{CONSIDERAÇÕES FINAIS}

Mais da metade dos municípios paulistas oferece algum tipo de incentivo a novos empreendimentos, não se observando um padrão espacial definido, visto que uma parcela significativa dos municípios de todas as regiões do Estado dispõe desses mecanismos.

Quando se desagregam os principais instrumentos de incentivo, verifica-se que as isenções de IPTU, ISS e isenções de taxas municipais - mecanismos estritamente tributários -, são utilizadas, sobretudo, pelos municípios maiores e/ou próximos à RMSP. Já as concessões e doações de terrenos são utilizadas, em especial, pelos municípios menores e/ou mais afastados do eixo mais industrializado do Estado.

Os mecanismos de restrição à instalação de empreendimentos são mais utilizados pelos municípios das RAs mais industrializadas e por municípios de médio e grande portes. Estes, em sua maioria, já enfrentam sérios problemas ambientais e por isso têm que se mostrar mais vigilantes quanto à instalação de investimentos que possam impactar negativamente o meio ambiente. Os municípios buscam impedir, em particular, a instalação de unidades industriais poluidoras. O principal instrumento, para tanto, é a legislação específica. O instrumental tributário é pouco utilizado com esse propósito.

Observa-se, em síntese, que tem crescido a disputa nas municipalidades, com generalização de políticas municipais de atração industrial. Todavia, os incentivos municipais, ainda menos que os estaduais, não são suficientes para uma estratégia bem-sucedida a longo prazo. A recente decisão da Embraer de realizar grande investimento em Gavião Peixoto, pequeno município da região de Araraquara, reforça esta hipótese, ao mesmo tempo em que não desmonta a afirmação de que estão sendo privilegiados os municípios pólos regionais ou seus entornos imediatos.
Nos setores intensivos em conhecimento, cada vez mais deixam de ser preponderantes, para a estratégia empresarial de localização, os ganhos de escala - tão comuns no "regime fordista" de produção em massa. A localização passa a ser determinada pela existência de mão-de-obra qualificada, pela possibilidade de constituição de rede de fornecedores, por ganhos de escopo, pela proximidade do mercado consumidor, pela possibilidade de uma qualidade de vida "amena" para seus funcionários, entre outros.

Esses são os motivos que justificam a escolha da localização de novos empreendimentos em municípios de médio porte do interior paulista. É provável que num futuro próximo continuem prevalecendo esses mesmos fatores e que incentivos fiscais municipais permaneçam com um peso reduzidíssimo no processo de decisão locacional. Essa lógica prevalece sobretudo para a grande indústria de bens de consumo duráveis, responsável por parcela significativa dos novos investimentos.

\section{NOTAS}

1. Sobre a heterogeneidade dos municípios paulistas, ver Caiado (1995).

2. Sobre "guerra fiscal" entre Estados da Federação, ver Fundap (1999) e Alves (2001).

3. Este subitem foi escrito em parceria com Maria Abadia da Silva Alves.

\section{REFERÊNCIAS BIBLIOGRÁFICAS}

ALVES, M.A.S. Guerra fiscal e finanças federativas no Brasil: o caso do setor automotivo. 2001. Dissertação (Mestrado) - Universidade Estadual de Campinas, Instituto de Economia, Campinas, 2001.

CAIADO, A.S.D. Desconcentração industrial regional no Brasil (1985-1998): pausa ou retrocesso? Tese (Doutorado) - Instituto de Economia da Universidade de Campinas, Campinas, 2002.

. Dinâmica socioespacial e a rede urbana paulista. São Paulo em Perspectiva, São Paulo, Fundação Seade, v.9, n.3, p.4653, jul./set.1995.

FUNDAP. Guerra fiscal no Brasil: três estudos de caso: Minas Gerais, Rio de Janeiro e Paraná. São Paulo: Fundap, 1999.

PRADO, S.; CAVALCANTI, C.E.G. Aspectos da guerra fiscal no Brasil. São Paulo: Ipea/Fundap, 1998.

VARSANO, R. A guerra fiscal do ICMS: quem ganha e quem perde. Planejamento e Políticas Públicas, Brasília, Ipea, n.15, p.13-18, 1997.

Aurílio Sérgio Costa Caiado: Arquiteto, Analista da Fundação Seade e Professor da Universidade de Sorocaba. 